\title{
A new regulatory protein, KSRP, mediates exon inclusion through an intronic splicing enhancer
}

\author{
Hosung Min, ${ }^{1}$ Christoph W. Turck, ${ }^{4}$ Julia M. Nikolic, ${ }^{3}$ and Douglas L. Black ${ }^{1-3,5}$ \\ ${ }^{1}$ Molecular Biology Institute, ${ }^{2}$ Department of Microbiology and Molecular Genetics, and ${ }^{3}$ Howard Hughes Medical Institute, \\ University of California at Los Angeles, Los Angeles, California 90095-1662 USA; ${ }^{4}$ Howard Hughes Medical Institute, \\ Department of Medicine and Cardiovascular Research Institute, University of California at San Francisco, San Francisco, \\ California 94143-0724 USA
}

We have purified and cloned a new splicing factor, KSRP. KSRP is a component of a multiprotein complex that binds specifically to an intronic splicing enhancer element downstream of the neuron-specific c-src N1 exon. This $75-\mathrm{kD}$ protein induces the assembly of five other proteins, including the heterogeneous nuclear ribonucleoprotein $F$, onto the splicing enhancer. The sequence of the KSRP cDNA indicates that the protein contains four K homology RNA-binding domains and an unusual carboxy-terminal domain. KSRP is similar to two proteins, FUSE-binding protein and P-element somatic inhibitor. KSRP is expressed in both neural and non-neural cell lines, although it is present at higher levels in neural cells. Antibodies specific for KSRP inhibit the splicing of the N1 exon in vitro. Moreover, this inhibition of N1 splicing can be rescued by the addition of purified KSRP. KSRP is likely to regulate splicing from a number of intronic splicing enhancer sequences.

[Key Words: Alternative splicing; regulatory protein; KSRP; intronic splicing enhancer; RNA-binding protein]

Received October 22, 1996; revised version accepted March 4, 1997.

The pre-mRNA splicing reaction is an important control point in the regulation of gene expression (Moore et al. 1993; Rio 1993; Kramer 1995). Alternative splicing patterns can be regulated in a highly tissue- or developmentspecific manner and can generate important functional variation in an encoded protein. The choice of splicing pattern is thought to be determined by proteins that bind to regulatory sequences in the pre-mRNA and act to enhance or suppress spliceosome assembly at specific splice sites. Although several proteins have been identified in Drosophila that act in this way, the regulatory molecules that direct alternative splicing are mostly unknown and poorly understood (McKeown 1992; Hodges and Bernstein 1994; Inoue et al. 1995; Adams et al. 1996).

Positive-acting splicing regulatory sequences generally can be classified by their location in either exons or introns. Exonic splicing enhancers are sequences, found in certain exons, that can stimulate spliceosome assembly at the upstream 3' splice site of the exon (Fu et al. 1991; Lavigueur et al. 1993; Sun et al. 1993; Watakabe et al. 1993; Caputi et al. 1994; Dirksen et al. 1994; Staknis and Reed 1994; Tanaka et al. 1994; Tian and Maniatis 1994; Ramchatesingh et al. 1995; Wang et al. 1995). Exonic enhancers are usually purine-rich sequences whose ac-

${ }^{5}$ Corresponding author.

E-MAIL dougb@microbio.lifesci.ucla.edu; FAX (310) 206-4042. tivity is mediated, at least in part, by a group of molecules known as SR (serine- and arginine-rich) proteins. These are a large family of proteins, found in both Drosophila and mammalian cells, each containing a serine- and arginine-rich domain and one or more RNA-binding domains of the ribonucleoprotein or RNP-type (Fu 1995; Manley and Tacke 1996; Valcárcel and Green 1996). SR proteins have been implicated in many aspects of the splicing process. Most notably, they have been shown to bind to exonic enhancers and in one case to synergize with more specialized regulatory proteins bound to the enhancer (Lynch and Maniatis 1996).

Although less understood than exonic splicing enhancers, there are also intronic sequences that activate splicing (Balvay et al. 1992; Black 1992; Huh and Hynes 1994; Del Gatto and Breathnach 1995; Lou et al. 1995; Sirand-Pugnet et al. 1995; Carlo et al. 1996; Ryan and Cooper 1996). Intronic splicing enhancers are often found in the introns downstream of regulated exons and are required for the splicing of these exons. They have been identified in an array of transcripts, including c-src, fibronectin, $\beta$-tropomyosin, fibroblast growth factor receptor, cardiac troponin $\mathrm{T}$, and calcitonin/calcitonin gene-related peptide. These intronic enhancers contain diverse sequence elements that are often repeated and show a variety of tissue specific regulation. So far, SR 
proteins have not been found to bind to these sequences. Although the c-src intronic enhancer binds to a complex of proteins, including the heterogeneous nuclear ribonucleoprotein $\mathrm{F}$ (hnRNP F), other proteins that mediate splicing through these regulatory sequences are unknown (Min et al. 1995).

The mammalian nervous system is especially rich in regulated splicing events, and many important gene transcripts are generated in neural-specific spliced forms (Burke et al. 1992). In one example, the pre-mRNA for the proto-oncogene c-src contains a short 18-nucleotide exon, $\mathrm{Nl}$, that is spliced into the mRNA in neuronal cells but is excluded in non-neuronal cells (Levy et al. 1987; Martinez et al. 1987). This alternative splicing results in a 6-amino-acid insertion within the conserved $\mathrm{SH} 3$ domain of Src protein tyrosine kinase. The mouse src N1 exon has proven to be a useful model for understanding both neural-specific splicing and the regulation of short cassette exons in general (Black 1991, 1992; Chan and Black 1995; Min et al. 1995).

The regulation of the $\mathrm{Nl}$ exon has been analyzed both in vivo and in vitro (Black 1991, 1992). N1 exon inclusion in neurons is under the positive control of an intronic regulatory sequence. The core conserved sequence, called the downstream control sequence (DCS), is between 38 and 70 nucleotides downstream of the N1 5' splice site (Black 1992; Min et al. 1995). In neuronal WERI-1 cell extracts, a complex of proteins assembles specifically onto a DCS RNA (Min et al. 1995), and competition experiments indicate that the binding of this DCS complex is required for $\mathrm{Nl}$ exon splicing in vitro. UV cross-linking identifies at least six components of the DCS complex: the 53-kD hnRNP F, several other non-cell-type specific proteins of $90,58,43$, and $28 \mathrm{kD}$, and a $75-\mathrm{kD}$ protein that by cross-linking appears neuralspecific. Finally, antibody to the hnRNP F protein inhibits N1 exon splicing in vitro, suggesting a crucial role for this protein in activating splicing by the DCS. To understand their assembly and their role in splicing regulation, we have continued to characterize the proteins in this DCS complex.

In the work presented here, we purified and cloned the $75-\mathrm{kD}$ protein from the DCS complex. Although apparently not neural specific, we show that this protein is a key component in the cooperative assembly of the DCS complex and is required for N1 exon splicing in vitro. The cDNA sequence for the $75-\mathrm{kD}$ protein identifies it as a new protein containing four $\mathrm{K}$ homology $(\mathrm{KH}) \mathrm{RNA}-$ binding domains (Siomi et al. 1994) and an unusual carboxy-terminal domain. We call this protein a $\mathrm{KH}$-type splicing regulatory protein (KSRP). This type of protein may be involved in activating splicing through an array of intronic splicing enhancer sequences.

\section{Results}

\section{The isolation of $p 75 / K S R P$}

The DCS sequence binds to a complex of proteins, including six that cross-link to the RNA: p90, p75 doublet, p58, p53 (hnRNP F), p43, and p28 (Min et al. 1995) (see
Fig. 1C, lane 1). To characterize these proteins further, we set out to purify them from WERI-1 cell extract (Fig. 1A). A WERI-1 nuclear extract fraction active in assembling the DCS complex was prepared as described previously (Min et al. 1995). Briefly, WERI-1 nuclear extract was cleared with a high-speed spin and then precipitated in $40 \%$ ammonium sulfate. The ammonium sulfate pellet fraction was resuspended in in vitro splicing buffer DG (see Materials and Methods and Min et al. 1995) and used for RNA affinity chromatography.

An RNA affinity column was prepared containing the DCS RNA sequence. The ammonium sulfate pellet fraction was loaded onto the column, and the column was washed extensively with the loading buffer. Bound proteins were then step eluted in $0.3,0.6,1.0$, and $2.0 \mathrm{M} \mathrm{KCl}$. The resulting fractions were dialyzed in buffer DG and used for various assays.

The fractions resulting from the RNA affinity column were tested for DCS complex formation using the RNA gel mobility shift assay (Fig. 1B). It was shown previously that the ammonium sulfate pellet fraction retained all six proteins that constitute the DCS complex. All four affinity fractions $(0.3,0.6,1.0$, and $2.0 \mathrm{M} \mathrm{KCl})$ failed to form the DCS complex or any smaller complex (Fig. 1B, lanes 2-5). This suggested that components of the DCS complex were being separated into different fractions and that a combination of proteins was required for the stable binding of the complex. Strikingly, when the 0.3 and $2.0 \mathrm{M} \mathrm{KCl}$ fractions were mixed, the ability to form the DCS complex was reconstituted (Fig. 1B, lane 6). Other combinations of two fractions failed to form a complex (data not shown).

To determine which of the proteins in the DCS complex were present in each fraction, UV cross-linking assays were performed with each of the RNA affinity fractions. It was shown previously that the binding of the DCS proteins can be observed by UV cross-linking even when complex assembly is not observed by the gel mobility shift assay (Min et al. 1995). Although the $0.3 \mathrm{M}$ $\mathrm{KCl}$ fraction failed to form any complex, it contained all of the proteins in the DCS complex except the $75-\mathrm{kD}$ doublet band. These included the p90, p58, hnRNP F, p 43 , and p28 proteins (Fig. 1C, lane 2). In contrast, the 2.0 $\mathrm{M} \mathrm{KCl}$ fraction showed cross-linking only of the $75-\mathrm{kD}$ doublet, although this binding was weak (Fig. 1C, lane 3). When the 0.3 and $2.0 \mathrm{M} \mathrm{KCl}$ fractions were mixed before the UV cross-linking reaction, all six proteins were observed cross-linking (Fig. 1C, lane 4). Interestingly, the cross-linking of the p75 doublet increased significantly in the $0.3 / 2.0 \mathrm{M}$ mixture compared with the $2.0 \mathrm{M}$ fraction alone (Fig. 1C, cf. lanes 3 and 4).

To determine its purity, each RNA affinity fraction was analyzed by SDS-gel electrophoresis and silver stained. As expected, the $0.3,0.6$, and $1.0 \mathrm{M}$ fractions are still quite crude, containing many proteins (Fig. 1D, lanes 2,3; data not shown). However, the $2.0 \mathrm{M}$ fraction is very clean, containing a doublet at $75 \mathrm{kD}$ and a single band at $\sim 70 \mathrm{kD}$ (Fig. 1D, lanes 4,5 ). The silver-stained $75-\mathrm{kD}$ doublet band comigrated exactly with the UV cross-linked doublet band. 

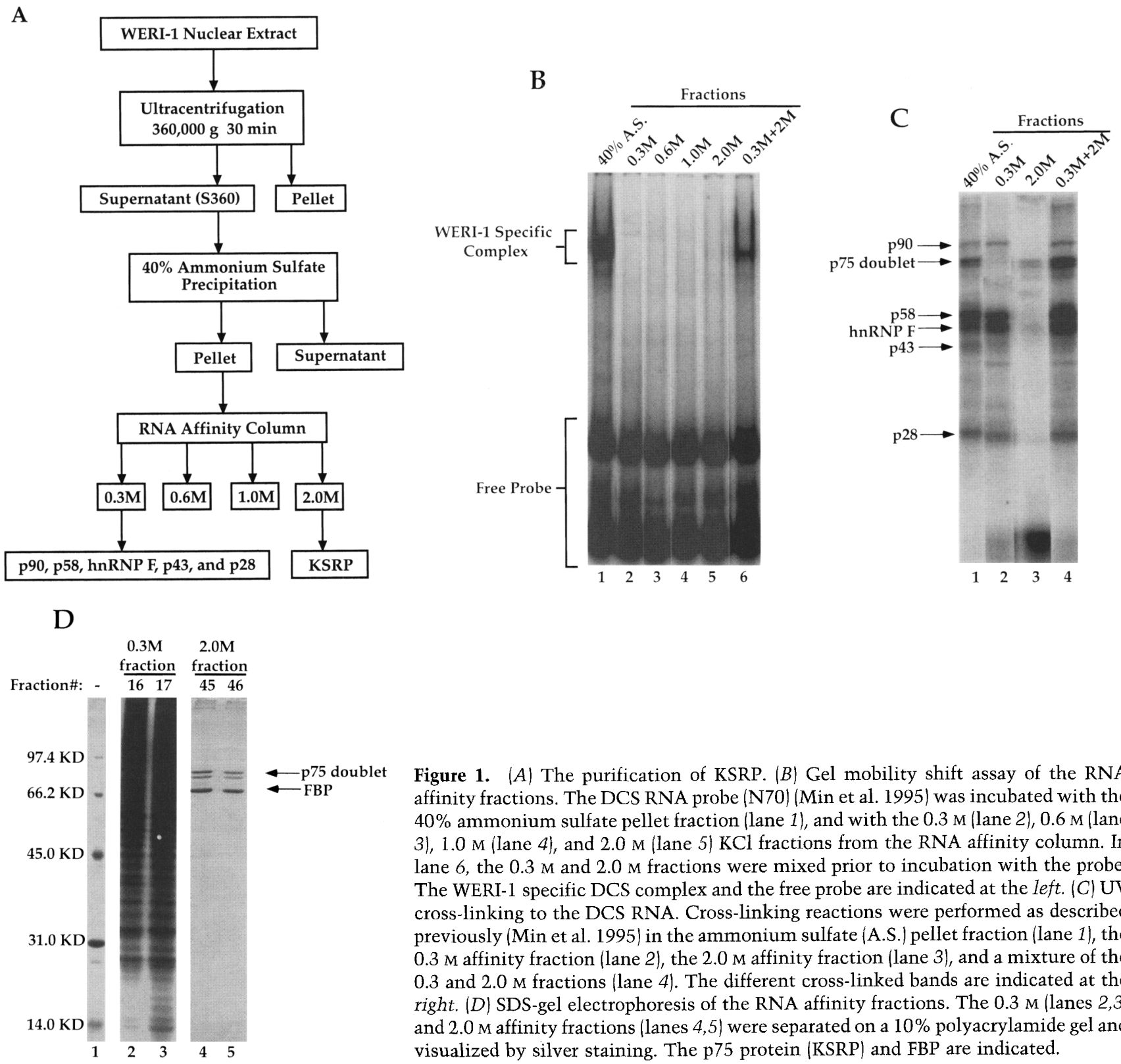

Figure 1. (A) The purification of KSRP. (B) Gel mobility shift assay of the RNA affinity fractions. The DCS RNA probe (N70) (Min et al. 1995) was incubated with the $40 \%$ ammonium sulfate pellet fraction (lane 1), and with the $0.3 \mathrm{M}$ (lane 2), $0.6 \mathrm{M}$ (lane 3), $1.0 \mathrm{M}$ (lane 4), and $2.0 \mathrm{M}$ (lane 5) $\mathrm{KCl}$ fractions from the RNA affinity column. In lane 6 , the $0.3 \mathrm{M}$ and $2.0 \mathrm{M}$ fractions were mixed prior to incubation with the probe. The WERI-1 specific DCS complex and the free probe are indicated at the left. $(C)$ UV cross-linking to the DCS RNA. Cross-linking reactions were performed as described previously (Min et al. 1995) in the ammonium sulfate (A.S.) pellet fraction (lane 1), the $0.3 \mathrm{M}$ affinity fraction (lane 2), the $2.0 \mathrm{M}$ affinity fraction (lane 3), and a mixture of the 0.3 and $2.0 \mathrm{M}$ fractions (lane 4). The different cross-linked bands are indicated at the right. (D) SDS-gel electrophoresis of the RNA affinity fractions. The $0.3 \mathrm{M}$ (lanes 2,3) and $2.0 \mathrm{M}$ affinity fractions (lanes 4,5 ) were separated on a $10 \%$ polyacrylamide gel and visualized by silver staining. The p75 protein (KSRP) and FBP are indicated.

The combined results of the gel mobility shift and the UV cross-linking experiments indicate that the p 75 protein is an essential factor in the assembly of the DCS complex and that it acts in a cooperative manner to induce or stabilize the assembly of the other proteins in the complex.

\section{The cloning of $p 75 / K S R P$ cDNAs}

Because of its ability to induce the assembly of the five other proteins onto the DCS RNA, we were very interested in the identity of the $75-\mathrm{kD}$ protein. A sample of the $2 \mathrm{~m}$ fraction containing $\sim 20 \mu \mathrm{g}$ of protein was concentrated by trichloroacetic acid precipitation and separated on an SDS gel. The proteins in the gel were trans- ferred to a polyvinylidene difluoride (PVDF) membrane, subjected to tryptic digestion, and separated by reversephase high-pressure liquid chromotography (HPLC). The two $75-\mathrm{kD}$ bands yielded nearly identical HPLC peptide profiles, indicating that the two bands represent highly related proteins (data not shown). From the lower band of the doublet, 10 peptides were purified and sequenced by automated Edman degradation (Fig. 2). Three peptides from the upper band were also sequenced and found to be identical to peptides from the lower band (data not shown). Searching the sequence databases with these peptides indicated that $\mathrm{p} 75$ was a new protein but related to several known proteins (see below).

The $70-\mathrm{kD}$ band was also digested with trypsin, and five peptides were sequenced. All five peptides $(15,19,9$, 


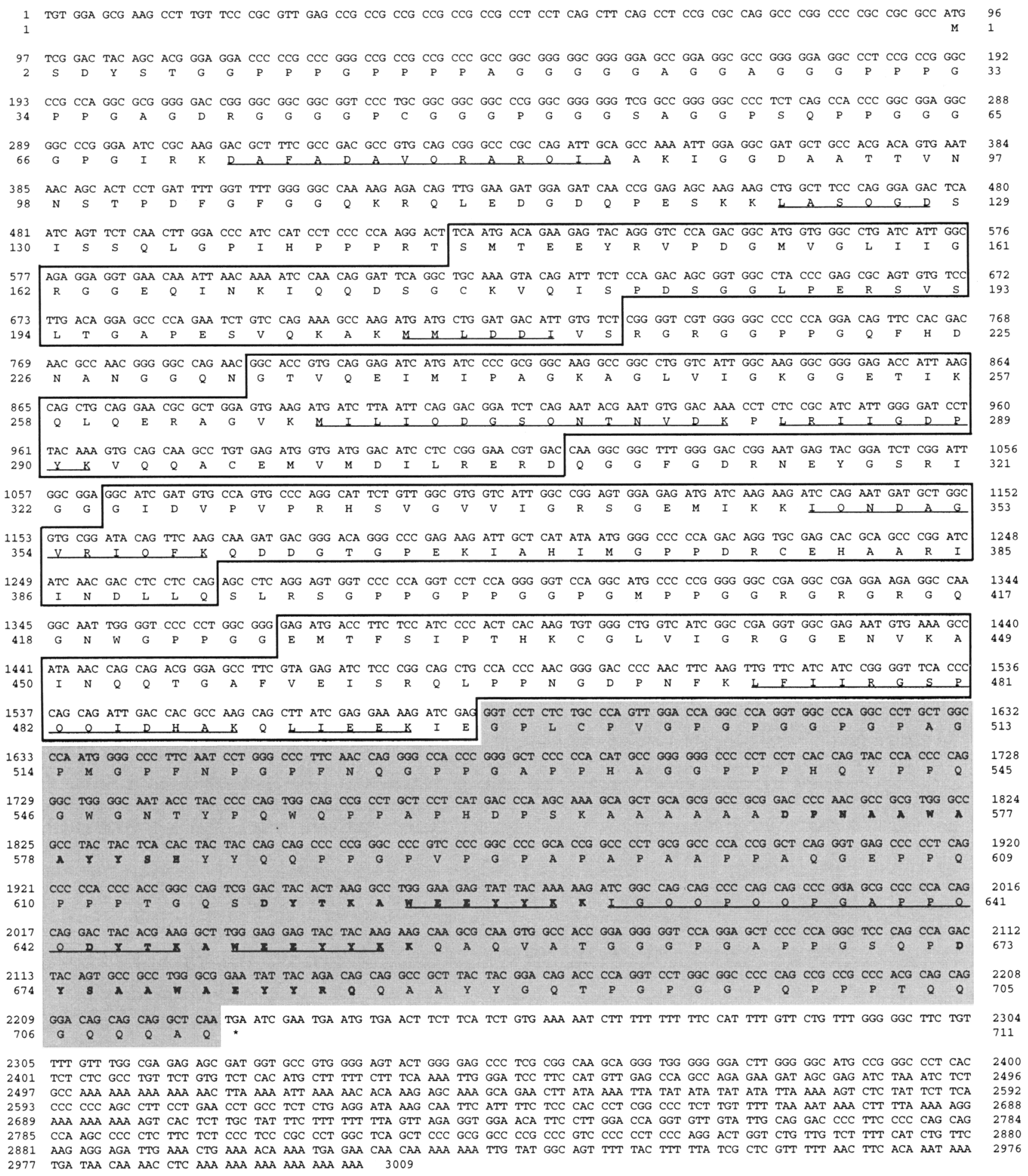

Figure 2. Composite DNA sequence and predicted amino acid sequence of the genomic and KSRP cDNA clones. The sequence from the genomic clone extends from nucleotides 1 to 238 . The L20-1 cDNA sequence extends from nucleotides 239 to 2513 . The remaining sequence is from other KSRP cDNA clones. Sequences of tryptic peptides from the purified protein are underlined. The four KH domains are boxed. The carboxy-terminal domain rich in $P, G, A$, and $Q$ is shaded. The DYTKAWEEYYKK repeated element and its degenerate copies are in boldface type. $\left(^{\star}\right)$ A termination codon.

9, and 13 amino acids in length) matched the far upstream sequence element (FUSE) binding protein (FBP) (data not shown) (Duncan et al. 1994). This protein also turned out to be related to p75/KSRP (see below). 
Several degenerate DNA oligonucleotides were designed by back translating the $\mathrm{p} 75$ peptide sequences and used in a PCR to amplify cDNA from WERI-1 cells. One pair of oligonucleotides generated an amplified DNA fragment of $660 \mathrm{bp}$ (nucleotides 307-966; Fig. 2). The sequence of this DNA fragment, when translated, contained the sequence of three peptides from the purified protein in addition to the peptides used for the amplification primers (Fig. 2).

To obtain full-length cDNAs, we made cDNA libraries from two human neural cell lines, the WERI-1 retinoblastoma and the LAN-5 neuroblastoma. These libraries were probed with the 660-bp PCR fragment. Several 2.2to $2.6-\mathrm{kB}$ cDNA clones were obtained from the two libraries (Fig. 2). Other overlapping clones were also obtained (data not shown).

The entire sequence of several clones (W8-1, L10-2, and L20-1) was determined. These clones contained long open reading frames (ORFs) extending to the $5^{\prime}$ end of the clone without an initiator methionine codon and are thus missing amino acids from the amino terminus of the protein.

Screening 25 more p75/KSRP cDNAs from the two libraries failed to identify a full-length clone. To obtain sequence farther 5', we used the technique of rapid amplification of cDNA ends (RACE) (Frohman 1993) to obtain a clone that extends 110 nucleotides upstream from the end of L10-2. This RACE clone was used to screen a human genomic library for the exons from the $5^{\prime}$ end of the gene. The sequence of the $5^{\prime}$-most exon in the genomic clone extended the ORF of L10-2 some 50 amino acids upstream to an AUG codon. This codon has a good match to the Kozak consensus for initiator AUG codons (7/9 match; Kozak 1986) and predicts a protein of $73 \mathrm{kD}$, very close to the $75 \mathrm{kD}$ estimated by gel electrophoresis. Upstream of this AUG the ORF is broken by a stop codon (data not shown). Moreover, a comparison of this predicted amino-terminal sequence to two related proteins indicates that this is likely the correct initiator AUG (see Fig. 3). The entire $5^{\prime}$ region both upstream and downstream of the AUG is extremely GC-rich. The inability of reverse transcriptase to extend through this region is likely the reason it was difficult to obtain a full-length cDNA clone.

Although the sequences of clones W8-1, L10-2, and L20-1 are nearly identical, there are differences at the $3^{\prime}$ ends. From a comparison with the genomic sequence, clones W8-1 and L20-1 appear more fully spliced than L10-2 and so the W8-1/L20-1 sequence is reported. It is not yet clear how the two bands in the KSRP doublet seen on protein gels differ from each other, but examination of the EST database indicates that there may be splicing variation at the carboxyl terminus (data not shown).

\section{p75/KSRP contains KH domains}

The composite ORF of the cDNA and genomic sequences encodes a 711-amino-acid polypeptide containing several distinctive features. All 10 peptide sequences obtained from the purified protein are present (Fig. 2). The protein contains a central region of four tandemly repeated $\mathrm{KH}$ domains (Fig. 2). The $\mathrm{KH}$ domain was first identified in the hnRNP $\mathrm{K}$ protein and found to be necessary for the RNA binding of the hnRNP K and FMR1 proteins (Siomi et al. 1993, 1994). Thus, the central region of p75 containing these domains, is likely to be responsible for binding to the DCS RNA sequence. Because of the presence of the $\mathrm{KH}$ domains and the functional data described below, we now call the p75 protein KSRP.

KSRP contains a proline/glycine-rich amino terminus and an unusual carboxy-terminal domain that is rich in the 4 amino acids proline $(25 \%)$, glycine (14\%), alanine $(14 \%)$, and glutamine $\{13 \%\}$ (Fig. 2$)$. Within this large carboxy-terminal domain are two repeats of the sequence DYTKAWEEYYKK (Fig. 2). These identical repeats are flanked by more degenerate copies of the same sequence. The function of this domain and these repeated motifs are not clear.

The KH domain is defined by an $\sim 70$-amino-acid sequence that folds into $\alpha \beta \alpha \alpha \beta \beta \alpha$ structure. The most conserved sequence within the KH domain is a GKXG motif that is usually preceded by LVI (Musco et al. 1996). One of the KSRP KH domains contains GKXG, whereas the other three contain GRXG. These are preceded by LVI, VVI, and LII. KSRP is similar to a number of proteins within the sequences that define the $\mathrm{KH}$ domain. In addition, the KSRP is especially similar to two known proteins. One protein is the human FBP (Duncan et al. 1994). FBP was identified as binding to single-stranded DNA (ssDNA) derived from the c-myc promoter and is thought to enhance transcription of the $c-m y c$ gene. The second protein similar to KSRP is the P-element somatic inhibitor protein (PSI) (Siebel et al. 1994, 1995). PSI is a tissue-specific splicing factor in Drosophila, where it binds in a complex of proteins to the P-element premRNA and is thought to repress P-element third intron (IVS3) splicing in somatic cells. Pairwise analysis indicates a $70 \%$ amino acid sequence identity between KSRP and FBP (Fig. 3A) and 35\% identity between KSRP and PSI (Fig. 3B). The similarity is more pronounced in the $\mathrm{KH}$ domains, where KSRP and FBP are $74 \%$ identical and KSRP and PSI are $48 \%$ identical (Fig. 3A,B). However, on either side of the $\mathrm{KH}$ region there are also significant blocks of similarity in all three proteins. Most notable is the DYTKAWEEYYKK repeat. The FBP has one exact copy of this sequence in its carboxy-terminal region as well as degenerate copies, and PSI contains two copies of DYSAQW(I/A)EYY(K/R)(Q/S) (Fig. 3A,B). These conserved motifs adjacent to the KH domains define these proteins as a new family of regulatory molecules.

\section{KSRP is expressed in both neural and non-neural cell lines}

Previously we observed the $75-\mathrm{kD}$ KSRP cross-linking to the DCS RNA in a neural cell extract but not in nonneuronal extract (Min et al. 1995). To determine whether this cross-linking pattern was attributable to the neural- 
A

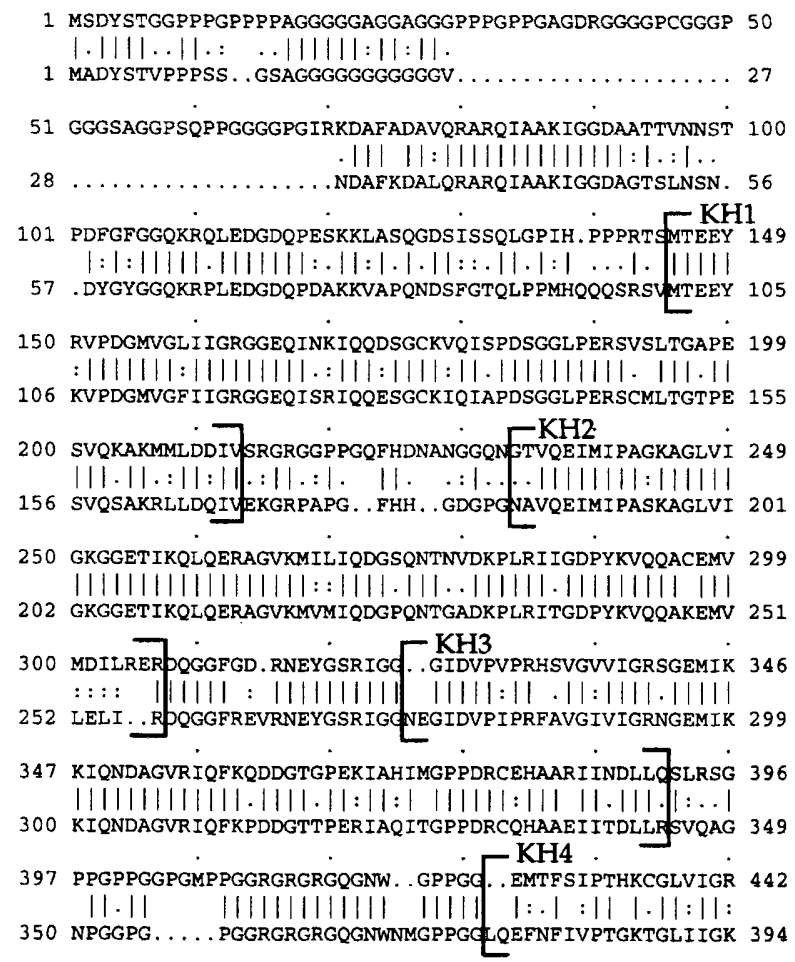

443 GGENVKAINQQTGAFVEISRQLPPNGDPNFKLFIIRGSPQQIDHAKQLIE 492 $|1| .: 1.1 .11 .11: 1: 1 .|1|:|1|:|11.111 .111| 1.1: 1111$ 395 GGETIKSISQQSGARIELQRNPPPNADPNMKLFTIRGTPOQIDYARQLIE 444

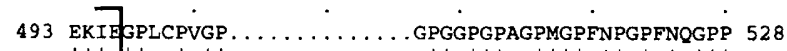
|| $|:| 1:|:| 1|| 1 ..|1|:|||||:||:|:||||$, 445 EKI GGPVNPLGPPVPHGPHGVPGPHGPPGPPGPGTPMGPYNPAPYNPGPP 494

529 GAPPHAGGPPPHQYPPQGWGNTYPQWQPPAPHDPSKAAAAAADPNAAWAA 578 1::1|: ||$\cdot|:||||||\cdot||:|||||, \cdot|| \cdot||: \ldots: .,|||| \mid$

495 GPAPHG. . . PPAPYAPQGWGNAY PHWQQQAPPDPAKAGTDPN . . SAAWAA 539

579 YYSKYYQ ... QPPGPVPGPAPAPAAPFAQGEPPQPPPTGQSDYTKAWEEY 625

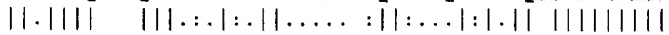
540 YYAHYYQQQAQPPPAAPAGAPTTTQTNGQGDQQNPAPAGQVDYTKAWEEY 589

626 YKKIGQQPQQPGAPPQQDYTKAWEEYYKKQAQVATGGGPGAPPGSQPDYS 675

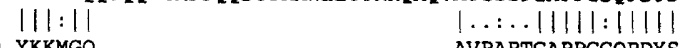
590 YKKMGQ .....................................

676 AAWAEYYRQQAAYYGQTPGPGGPQPPPTQQGQQQAQ 711

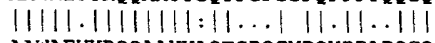

613 AAWAEHYRQQAAYYAQTSPQGMPQHPPAPQGQ ... 644

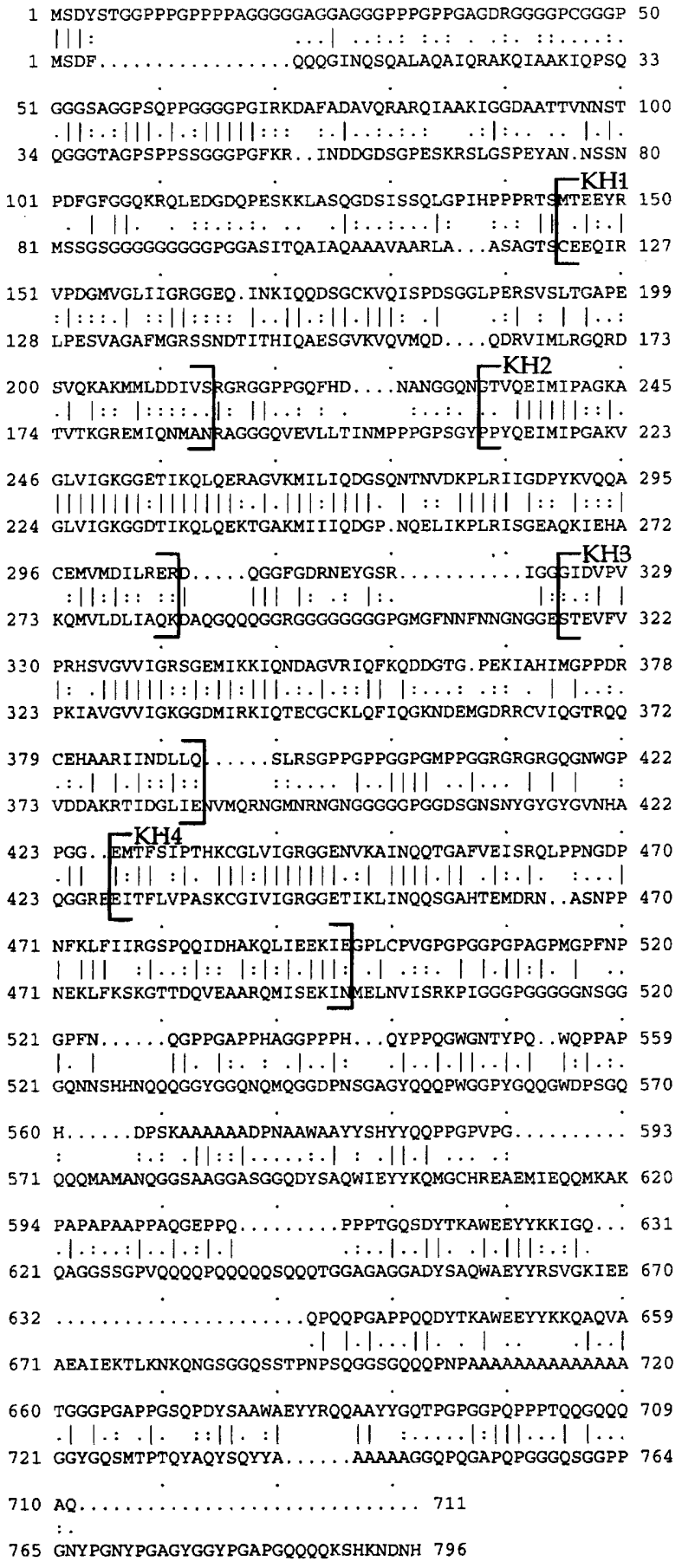

QOOGINOSQALAOATORAKOIAAKIOPSQ

GGGSAGGPSQPPGGGGPGIRKDAFADAVQRARQIAAKIGGDAATTVNNST 100 $.||: .:|||.| .:||||::: \quad:|\ldots: . . . \quad .:|: \ldots \ldots|$. 34 QGGGTAGPSPPSSGGGPGFKR. . INDDGDSGPESKRSLGSPEYAN. NSSN 80

101 PDFGFGGQKRQLEDGDQPESKKLASQGDSISSQLGPIHPPPRT WTEEYR 150 MSSGSGGGGGGGGPGGASITQAIAQAAAVAARLA. . ASAGT CEEEQIR 12

1 VPDGMVGLIIGRGGEQ. INKIQQDSGCKVQISPDSGGLPERSVSLTGAPE 199 $:|:::|::||::::|\ldots||.:|||||:. .|\quad .:|:|| \ldots$ 128 LPESVAGAFMGRSSNDT ITHIQAESGVKVQVMQD. . . QDRVIMLRGQRD 173 200 SVQKAKMMLDDIVSRGRGGPPGQF'HD. . . NANGGQN FTVOETMIPAGKA 245

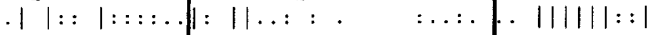
GLVIGKGGDTIKQLQEKTGAKMI IIQDGP. NQELIKPLRISGEAQKIEHA 272 296 CEMVMDILRER . . . . QGGFGDRNEYGSR . . . . . . IGGGIDVPV 329 $:||:|::::|||||:$ | |: . |: .: | | 273 KQMVLDL IAQ PAQGQQQGGRGGGGGGGGPGMGFNNFNNGNGGE \&TEVFV 322 330 PRHSVGVVIGRSGEMIKKIONDAGVR IOFKODDGTG. PEKIAHIMGPPDR 378 $|:||||||::|:||:|||.:| .::|||: \ldots: .::| \mid. \ldots:$ VDDAKRT IDGLIE JVMORNGMNRNGNGGGGGPGGDSGNSNYGYGYGVNHA 422

PGG. EMTFSIPTHKCGLVIGRGGENVKAINQQTGAFVEISRQLPPNGDP 470 $.|||:||:| .|\|:|||||||:|||||\cdot|||:.|| . \quad: \ldots$ QGGREITFLVPASKCGIVIGRGGETIKLINQQSGAHTEMDRN. . ASNPP 470

NFKLFIIRGSPQQIDHAKQLIEEKI GPLCPVGPGPGGPGPAGPMGPFNP 520

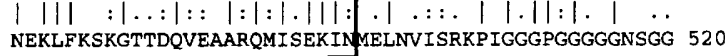

21 GPFN. . . . . QGPPGAPPHAGGPPPH, . OYPPQGWGNTYPQ. . WQPPAP 559 |. | ||. |:.:. . .. : .|.|.||.|.| |:|.: 521 GQNNSHENQOOGGYGGQNOMOGGDPNSGAGYQQQPWGGPYGQQGWDPSGQ 570

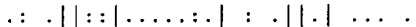

571 QQQMAMANOGGSAAGGASGGQDYSAQWIEYYKOMGCHREAEMIEQQMKAK 620

594 PAPAPAAPPAOGEPPO . . . . . . PPPTGOSDYTKAWEEYYKKIGQ . . 631

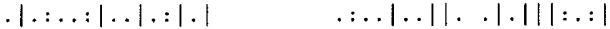
. |. . ..||. . . . . . . | 660 TGGGPGAPPGSOPDYSAAWAEYYROOAAYYGOTPGPGGPOPPPTQQGQQ0 709

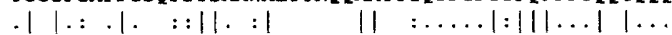
21 GGYGQSMTPTQYAQYSQYYA.... . AAAAAGGQPQGAPQPGGGQSGGPP 764

765 GNYPGNYPGAGYGGYPGAPGQQQQKSHKNDNH 796

Figure 3. Amino acid sequence comparison of KSRP with FBP $(A)$ and PSI $(B)$. The pairwise comparisons were performed by the GAP program in the GCG software package using the default scoring matrix. Vertical lines indicate identical residues. Nonidentical residues are noted with dots depending on their score from the mutational difference matrix (Schwartz and Dayhoff 1979). The KH domains are bracketed.

specific expression of KSRP, we performed Northern blot experiments. Total RNA from the neural LAN-5 and WERI- 1 cell lines and the non-neural HeLa and HEK cell lines were resolved on a gel and blotted to a membrane. The blot was probed with a portion of the KSRP cDNA. This probe detected a transcript of $\sim 4 \mathrm{~kb}$ in all four cell 
lines (Fig. 4A). In the neural cell lines WERI-1 and LAN-5 the intensity of the band was about three times higher than in the non-neural cell lines HeLa and HEK (Fig. 4A).

To examine further the expression of KSRP, Western blot experiments were performed. Rabbit polyclonal antibodies were raised to glutathione $S$-transferase (GST)KSRP fusion proteins (see Materials and Methods). Antiserum $\mathrm{C} 2742$ was raised against a fusion protein containing most of the $\mathrm{KH}$ region and the carboxyl terminus of KSRP. Antiserum $\mathrm{C} 2740$ is against $\mathrm{KH} 2, \mathrm{KH} 3$, and part of KH1. In lanes 1 and 2 of Figure 4B, the same total mass of protein from HeLa and WERI-1 nuclear extract was loaded on an SDS gel. This gel was electroblotted and probed with C2742 antiserum. As expected, C2742 recognized the KSRP doublet in both extracts (Fig. 4B, lanes 1,2). The serum also cross-reacted with a $70-\mathrm{kD}$ band, which is presumably the related FBP protein. Consistent with the Northern blot experiments, the KSRP doublet in WERI-1 extract is about three times more intense than in HeLa extract. This is in contrast to $70-\mathrm{kD}$ FBP band, which has similar intensity in both the HeLa and WERI-1 lanes. The C2740 antiserum gave a similar pattern in Western blots (data not shown). We conclude that although KSRP is more abundant in the neural cells, it is expressed in both. Thus, the differential cross-linking that we observe in cell extracts must arise from factors other than the relative levels of KSRP.

\section{The enhancer/protein complex is disrupted by anti-KSRP antibodies}

KSRP was identified as a component of a protein-RNA complex assembled on the DCS element (Min et al. 1995). To confirm that the cloned protein was needed in the formation of this complex, the assembly of the complex was assayed in the presence of anti-KSRP antibodies. Total immunoglobulin $G$ was purified from the C2742 and C2740 antisera on protein A-Sepharose. These antibodies were added to the WERI-1 extract prior to the addition of the DCS probe, and the formation of the DCS complex was assessed by the mobility shift assay. WERI-1 extract promotes assembly of two complexes onto the DCS RNA (Fig. 5, lane 1). The faster migrating constitutive complex was shown to be nonsequence-specific, whereas the slower migrating neural complex binds specifically to the DCS RNA (Min et al. 1995). Increasing amounts of either C2742 and C2740 antibodies disrupted formation of the DCS complex up to $90 \%$, indicating the need for KSRP in its assembly (Fig. 5, lanes 5-10). When KSRP antibodies were added to preassembled complexes, they did not affect the gel mobility of the DCS complex. Instead, the antibodies again caused disassembly of the complex (data not shown). In contrast, IgG from preimmune serum did not have an effect on the DCS complex formation (Fig. 5, lanes 2-4). The antibodies did not affect the binding of the nonspecific complex. An anti-FBP antibody also failed to disrupt the DCS complex, suggesting that FBP is not in the complex (data not shown).

\section{N1 exon splicing is inhibited by anti-KSRP antibodies}

To demonstrate the involvement of the KSRP in N1 splicing, an N1 exon splicing substrate (BS-7) was incubated in in vitro splicing reactions in the presence of the anti-KSRP antibodies. Previously, the BS-7 transcript was shown to be spliced efficiently in the presence of WERI-1 cell extract but not in HeLa cell extract alone. Purified C2742 and C2740 antibodies were incubated in nuclear extract prior to the addition of the BS-7 RNA substrate (Fig. 6A, lanes 2-7). Increasing amounts of either C2742 or C2740 antibody strongly inhibited N1 exon splicing. In contrast, preimmune serum had no effect on BS-7 splicing (Fig. 6A, lanes 8-10).

This inhibition of splicing by the anti-KSRP antibodies is transcript specific. A constitutively spliced adenovirus pre-mRNA was incubated in splicing extract pretreated with antibodies. Splicing of this substrate was not inhibited by the anti-KSRP antibodies at any of the concentrations tested (Fig. 6B). Similarly, splicing of two other

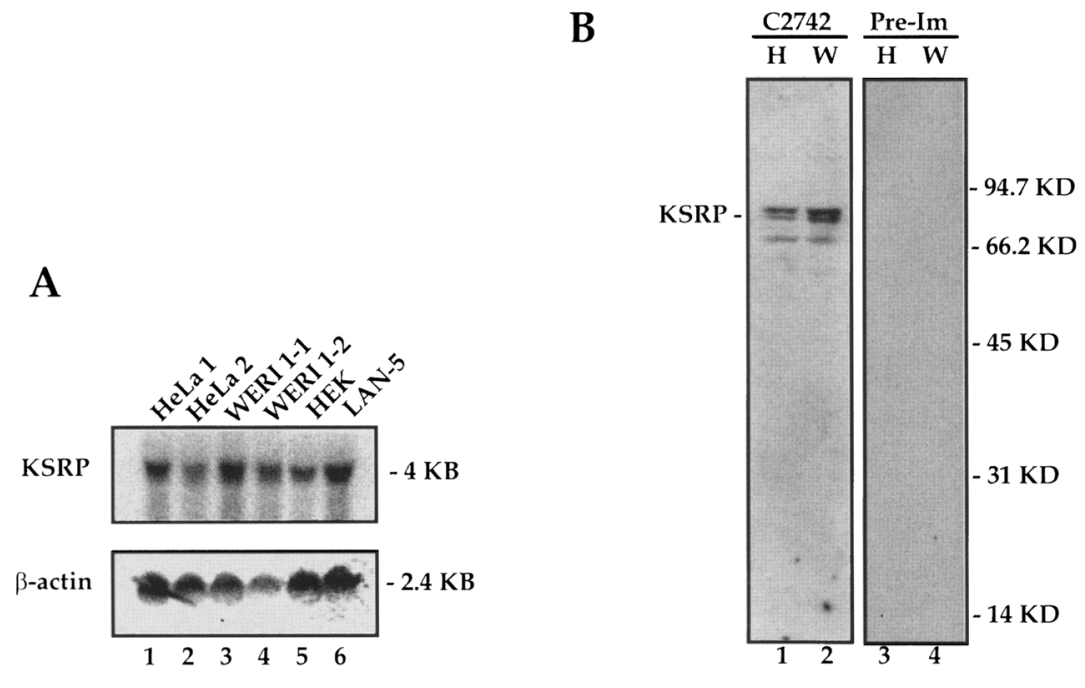

Figure 4. Expression of KSRP in neural and non-neural cell lines. (A) Northern blot of KSRP mRNA. Total RNA from two different HeLa cell preparations (lanes 1,2), two different WERI-1 cell preparations (lanes 3,4), HEK cells (lane 5), and LAN-5 cells (lane 6) were resolved on a $1 \%$ formaldehyde-agarose gel, transferred to a nylon membrane, and probed with a fragment of the KSRP cDNA \{top). After autoradiography, this membrane was stripped and probed with labeled a human $\beta$-actin cDNA (bottom). (B) Western blot of KSRP. Equal amounts of protein $(25 \mu \mathrm{g})$ from HeLa (lanes 1,3) and WERI-1 (lanes 2,4) nuclear extracts were separated by SDS-PAGE, transferred to a nitrocellulose membrane, and probed with C2742 anti-KSRP serum (lanes 1,2) or preimmune serum (lanes 3,4). The KSRP doublet is indicated. 


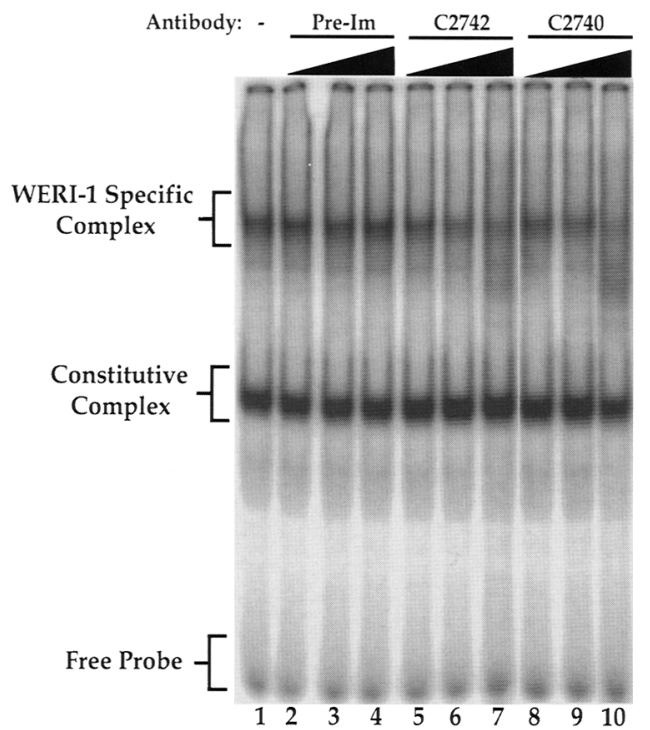

Figure 5. Disruption of the DCS complex by anti-KSRP antibodies. DCS RNA-binding reactions (Min et al. 1995) were carried out in the WERI-1 extract in the presence of no antibody (lane 1) or increasing amounts $(2.5,5.0$, or $7.5 \mu \mathrm{g})$ of preimmune (lanes 2-4), C2742 (lanes 5-7), or C2740 IgG (lanes 8-10). The position of the WERI-1-specific DCS complex, the nonspecific constitutive complex, and the free probe are indicated at left.

introns from the $s r c$ and $\beta$-globin genes was also unaffected by the KSRP antibodies (data not shown). KSRP is apparently needed for the splicing of certain introns but not others.

Next we tested whether the anti-KSRP antibodies were responsible for the inhibitory effect rather than other antigen specificities in the serum (e.g., anti-GST). Affinity-purified native KSRP and GST-KSRP fusion protein were preincubated with the antibody prior to the addition of extract. The KSRP-bound antibody failed to inhibit N1 exon splicing (Fig. 6C, lanes 3-5), indicating that KSRP is indeed the critical antigen recognized in the antibody inhibition experiments.

To determine whether the antibodies inhibit BS-7 splicing because of the cross-reaction with the FBP protein, we tested anti-FBP antibodies. These antibodies did not cross-react with KSRP in immunoblot experiments (data not shown). The anti-FBP antibodies failed to inhibit BS-7 splicing even at five times the concentration at which anti-KSRP antibodies inhibited /data not shown). It should be noted that the experiments with these anti-FBP antibodies have all yielded negative results. Although suggestive, they do not completely rule out FBP involvement in the DCS complex.

\section{N1 exon splicing can be rescued with purified KSRP after inhibition by KSRP antibodies}

To further test the functional role of KSRP in N1 splicing, we performed rescue experiments of the antibody inhibition reaction. Anti-KSRP antibody was used to in- hibit BS-7 splicing (Fig. 7, lane 2). Increasing amounts of affinity-purified native KSRP were then added. Strikingly, the purified KSRP was able to rescue the antibody inhibited BS-7 splicing (Fig. 7, lanes 3-5), whereas the GST-KSRP fusion protein failed to rescue the BS-7 splicing reaction (Fig. 7, lanes 6-8). This is in contrast to the experiment where the antigen is preincubated with the antibody (Fig. 6C). The ability of the native KSRP to rescue the inhibited reaction confirms its activity and supports its direct involvement in the N1 splicing reaction. Not surprisingly, the GST-KSRP fusion protein apparently is not active in the splicing reaction even though it can block the inhibition when prebound to the antibody.

\section{Discussion}

\section{A new splicing regulatory protein}

We have purified and cloned a new splicing regulatory protein KSRP. KSRP is essential for the assembly of a multiprotein complex onto the intronic splicing enhancer of the src Nl exon. We show that antibodies to KSRP inhibit both the assembly of the DCS complex and the in vitro splicing of the $\mathrm{N} 1$ exon, but not the splicing of other constitutively spliced introns. The KSRP antibodies do not bind to complexes already assembled onto the DCS. Instead, they block the complexes from assembling. For this reason, it is unlikely that the inhibition of splicing is a result of a steric block to spliceosome assembly, by antibodies bound to KSRP at the DCS, but instead is attributable to a specific requirement for KSRP in Nl splicing. Unambiguous proof of the KSRP role in DCS complex assembly will require the development of a fractionated system with extracts specifically lacking KSRP.

Although not required for all introns, it is likely that KSRP is involved in the splicing of other transcripts besides c-src. Many regulated exons are controlled by sequence elements in the downstream intron (Balvay et al. 1992; Black 1992; Huh and Hynes 1994; Del Gatto and Breathnach 1995; Lou et al. 1995; Sirand-Pugnet et al. 1995; Carlo et al. 1996; Ryan and Cooper 1996). These intronic splicing enhancers are diverse in sequence, but some have features in common with the src DCS. Regulated exons in $\beta$-tropomyosin and cardiac troponin $\mathrm{T}$ are affected by repeated intronic elements containing runs of G residues (Sirand-Pugnet et al. 1995; Carlo et al. 1996). The splicing of the EIIIB exon of fibronectin requires multiple copies of a UGCAUG element in the downstream intron (Huh and Hynes 1994). Both these G-rich and UGCAUG elements are found in the src DCS. It will be interesting to test the role KSRP plays in the splicing of these exons.

This enhancer complex is relatively large. The 33nucleotide core of the src DCS binds six proteins observable by UV cross-linking and perhaps others that do not cross-link (Min et al. 1995). The binding of all the proteins except KSRP is seen in HeLa extract. However, a stable complex is observable by gel shift only in WERI-1 
A

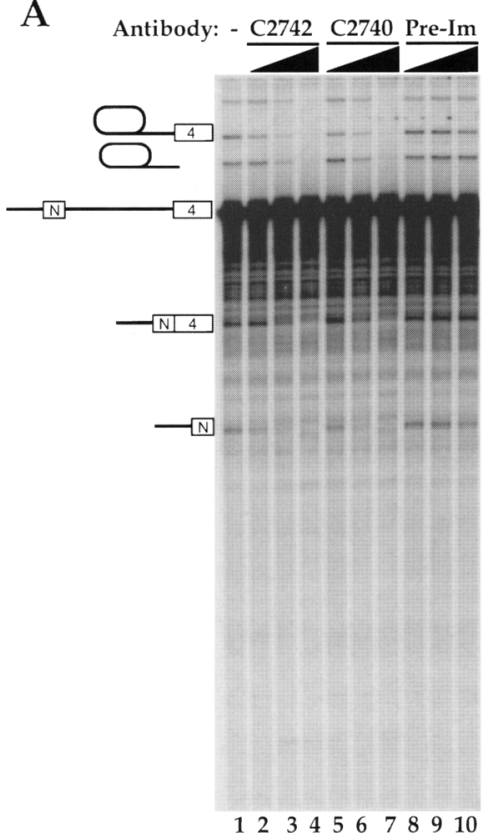

B

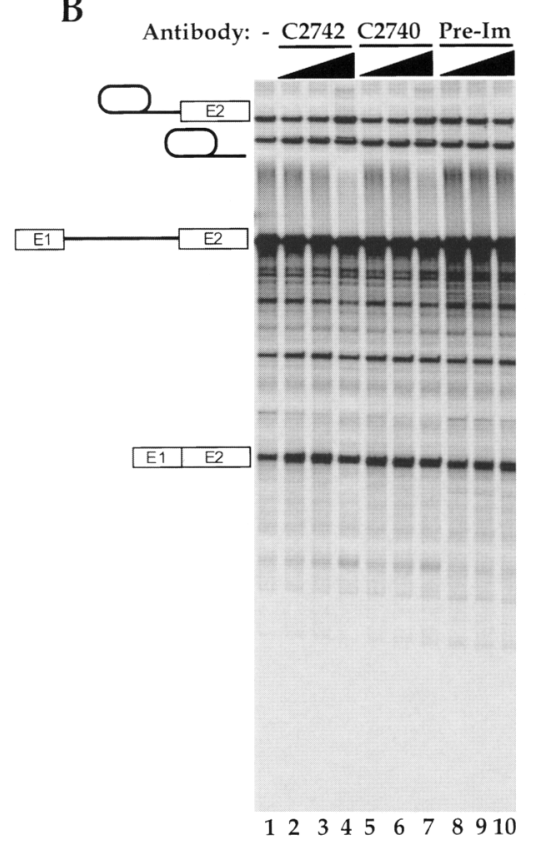

$\mathrm{C}$

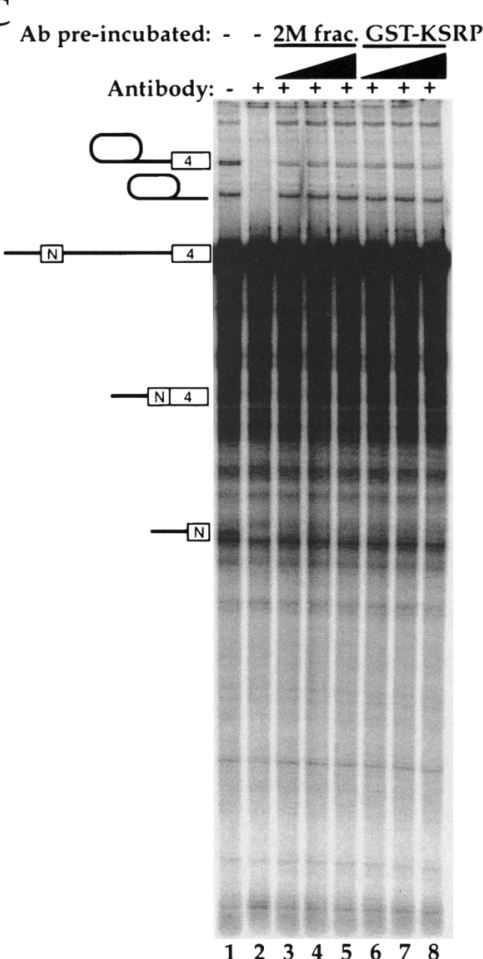

Figure 6. (A) Src N1 exon splicing is inhibited by anti-KSRP antibodies. Splicing reactions were carried out by incubating the BS-7 splicing substrate (Chan and Black 1995) in a HeLa/WERI-1 nuclear extract mixture alone (lane 1), or in extract preincubated with increasing amounts $(1.25,2.5$, or $5.0 \mu \mathrm{g})$ of IgG from the C2742 serum (lanes 2-4), the C2740 serum (lanes 5-7), or a preimmune serum (lanes $8-10$ ). The splicing reaction intermediates and products are diagramed at left. $(B)$ Adenovirus splicing in the presence of anti-KSRP antibodies. The reaction conditions for each lane are equivalent to $A$ except the pSPAd adenovirus substrate was used instead of BS-7. $(C)$ KSRP blocks the inhibition of splicing by the anti-KSRP antibody. The BS-7 N1 exon splicing substrate was incubated in HeLa/WERI-1 extract alone (lane 1) or in extract treated with $1.5 \mu \mathrm{g}$ of C2742 IgG (lanes 2-8). This KSRP antibody was preincubated with nothing (lane 2) or with increasing amounts of $2.0 \mathrm{M}$ affinity fraction (lanes 3-5) or purified GST-KSRP (lanes 6-8) before its addition to the extract. These reactions were run with half the amount of extract used in $A$, and exhibit lower overall splicing activity. The amount of added protein is 5, 10, or $23 \mathrm{ng}$ of purified KSRP and 20, 40, or $80 \mathrm{ng}$ of GST-KSRP. These are equal to the amounts used in Fig. 7. The amount of splicing recovered decreases linearly at $<2.5 \mathrm{ng}$ ( $33 \mathrm{fmoles}$ ) of purified KSRP or $<5 \mathrm{ng}$ (50 fmoles) of GST-KSRP.

extract and here KSRP can be observed by UV crosslinking. Because all the proteins including KSRP appear to be present in the HeLa extract, it is not clear what causes the neural specific assembly of the complex. There are several possible answers to this: (1) There is a neural-specific factor in the DCS complex that is not detected by UV cross-linking; (2) KSRP or another component is alternatively spliced or post-translationally modified in a neural-specific manner; and (3) there is no truly neural-specific protein, but subtle changes in the ratios of the non-tissue-specific proteins, coupled to a cooperative binding process, lead to the formation of the DCS complex only in neural cells. We are currently addressing these possibilities.

The most striking aspect of the assembly of the DCS complex is the requirement that KSRP be present for any of the proteins to bind stably. The $0.3 \mathrm{M}$ fraction contains at least five proteins in the complex and yet no partial complex is seen assembling by the gel shift assay. Similarly, the KSRP in the $2 \mathrm{~m}$ fraction does not show a gel shift complex and cross-links poorly to the DCS RNA. Adding KSRP to the other proteins causes the whole set to assemble onto the DCS RNA. The binding of these proteins is apparently highly cooperative.

Cooperative assembly of multiple regulatory proteins is seen in transcriptional enhancers and also in the regulated splicing of the Doublesex (dsx) transcript of Drosophila (Lynch and Maniatis 1995, 1996). An exonic splicing enhancer in the regulated $d s x$ exon is controlled by two specific regulatory proteins, Tra and Tra-2. Cooperative interactions among Tra, Tra2, and different SR proteins stabilize the assembly of different regulatory complexes on individual elements within the enhancer (Lynch and Maniatis 1996).

The binding of KSRP to the DCS RNA affinity column enabled us to separate KSRP from the rest of the complex. Although most of the DCS proteins eluted from the column at $0.3 \mathrm{M} \mathrm{KCl}, \mathrm{KSRP}$ eluted at $2 \mathrm{M} \mathrm{KCl}$. We also found that KSRP bound tightly to a poly(U) column. Because the affinity column was made by binding a 


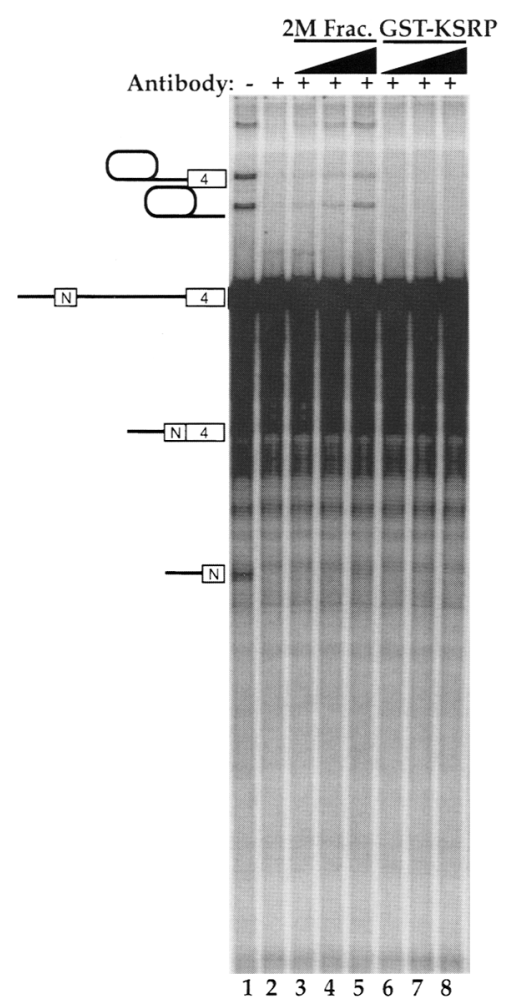

Figure 7. Rescue from the antibody inhibition of splicing by purified KSRP. BS-7 splicing reactions were performed as in Fig. $6 \mathrm{C}$. These reactions contained no antibody (lane 1) or $1.5 \mu \mathrm{g}$ of C2742 IgG to inhibit the BS-7 splicing activity (lanes 2-8). To this inhibited reaction, increasing amounts of $2.0 \mathrm{M}$ affinity fraction (lanes 3-5) or purified GST-KSRP (lanes 6-8) were added, prior to the addition of splicing substrate. Amounts of added protein are equal to those in Fig. 6C.

poly(A)-tailed DCS RNA to poly(U)-Sepharose, the tight binding of KSRP to the affinity column may be fortuitous. The other DCS proteins did not bind to poly $(\mathrm{U})$. KSRP is relatively abundant at $-1.7 \mu \mathrm{g} / \mathrm{ml}$ of nuclear extract, or $\sim 40,000$ molecules per cell, and possibly more. This is not unreasonable for a protein involved in RNA processing reactions, where the spliceosomal small nuclear ribonucleoproteins (snRNPs) are present at $10^{5}$ to $10^{6}$ copies per cell (Reddy and Busch 1988).

\section{The domain structure of KSRP}

Primary amino acid sequence indicates that the KSRP contains four $\mathrm{KH}$ domains. The $\mathrm{KH}$ domain was first identified in hnRNP $\mathrm{K}$ and shown to be essential for the RNA-binding activity of the protein (Siomi et al. 1993, 1994). The domain was subsequently identified in a wide array of nucleic acid-binding proteins from bacteria to humans. The solution structure of a $\mathrm{KH}$ domain from the Vigilin protein has been determined by nuclear magnetic resonance (NMR) (Musco et al. 1996). The KH repeat folds into a globular domain consisting of an antiparallel $\beta$-sheet packed against three $\alpha$-helices. The
RNA-binding surface is thought to be along the $\alpha$-helical face of the structure and a connecting loop. The amino and carboxyl termini of the domain are at opposite sides of the structure, allowing multiple domains to be easily linked together in a single polypeptide. It will be interesting to determine how the different $\mathrm{KH}$ domains in KSRP interact with the DCS sequence.

Beyond the homology to KH proteins in general, KSRP has significant similarity to two other proteins, PSI (Siebel et al. 1994, 1995) and FBP (Duncan et al. 1994). PSI was also identified as a splicing regulatory protein. However, unlike KSRP, PSI is a splicing repressor of the Drosophila P-element IVS3. A multiprotein complex containing PSI and hrp48 (a protein similar to mammalian hnRNP Al) binds to a regulatory sequence near the $5^{\prime}$ splice site of IVS3 (Siebel et al. 1994, 1995). This complex is thought to recruit the U1 snRNP to a pseudo- 5 ' splice site upstream of the correct 5 ' splice site to inhibit splicing. Although negatively acting, this mechanism of U1 recruitment for PSI may be similar to how the src DCS complex works (see below).

KSRP is also homologous to the FBP protein. FBP was identified as binding to ssDNA derived from the c-myc promoter sequence (Duncan et al. 1994). The carboxyterminal domain of FBP can act as a transcriptional activator when fused to the Gal4 DNA-binding domain (Duncan et al. 1996). The Levens laboratory independently has cloned a KSRP cDNA (called FBP2) by screening a library with an FBP probe at low stringency. They report that KSRP/FBP-2 also binds to ssDNA (DavisSmyth et al. 1996). In our assays we find that the KSRPcontaining complex is bound more stably to the DCS RNA than to either a DCS DNA or the FBP-binding site DNA (data not shown). However, given that KSRP contains four KH domains, it is quite possible that the protein could show specific binding to both RNA and ssDNA. This could lead to interesting models for the localization of splicing factors at certain transcription units and the coupling of RNA synthesis and processing.

KSRP contains a carboxy-terminal domain that is rich in proline, alanine, glycine, and glutamine. Within this domain are two repeats each of the sequences AAWA/A/ E/YY and DYTKAWEEYYKK. Similar repeats are also found in PSI and FBP. The function of these elements is not clear, but an attractive model is that this carboxyterminal domain engages in protein-protein interactions within the DCS complex.

\section{Models for the regulation of the N1 exon}

A number of mechanisms contribute to the skipping of the N1 exon in non-neural cells (Black 1991, 1992; Chan and Black 1995). The short length of the exon suppresses its inclusion, presumably by preventing the exon-bridging interactions that stimulate spliceosome assembly (Berget 1995; Black 1995). There also seem to be repressing protein factors that bind to CUCUCU elements on each side of the N1 exon and inhibit N1 splicing (Chan and Black 1995). In neurons, the repression is overcome by the activation from the DCS region (Black 1992; Min 
et al. 1995). This activation by the DCS is independent of any other src sequences (D.L. Black and E. Modafferi, unpubl.). A simple model for DCS function is that the protein complex assembling on the DCS recruits the U1 snRNP to the $5^{\prime}$ splice site of the N1 exon to initiate the splicing of the intron between exons $\mathrm{N} 1$ and N4. In the absence of the DCS complex, the spliceosome assembles between exons 3 and 4, skipping N1. In splicing reactions in vitro, the DCS affects primarily the intron downstream of $\mathrm{N} 1$ and not the intron upstream, implying action at the $5^{\prime}$ splice site. Moreover, this mechanism is reminiscent of the model for Drosophila P-element splicing where the PSI-containing complex recruits the UI snRNP to a specific site, but in this case the U1 binding is inhibitory (Siebel et al. 1992, 1994, 1995). Interestingly, the yeast alternative splicing factor MER1, which also contains a $\mathrm{KH}$ domain, is known to activate splicing of the MER2 transcript by strengthening a weak 5' splice site (Engebrecht et al. 1991; Nandabalan and Roeder 1995). Another newly identified splicing factor, SF1, contains a $\mathrm{KH}$ domain (Arning et al. 1996). This protein also contains a proline-rich carboxy-terminal domain and is required for prespliceosomal A complex formation.

Similar to transcriptional enhancers, the activity of intronic splicing enhancers is apparently mediated by whole sets of proteins. These may each recognize and bind to an individual sequence element or to multiple elements through multiple RNA-binding domains. The 33-nucleotide DCS RNA cross-links directly to six different proteins. One of these, hnRNP F, contains three RNA-binding domains. Another, KSRP, contains four RNA-binding domains. This multitude of RNA-binding domains creates a problem of where to put all of the proteins on the RNA. It may be that not all of these domains are used in assembling the DCS complex, as there are important regulatory sequences outside of the core DCS. On the other hand, a domain may recognize an RNA sequence already bound by another protein or each RNA-binding domain may recognize only a short sequence of RNA, perhaps only a few nucleotides. To achieve stable, specific binding with a very short recognition sequence, a protein would need, in addition to its own binding site, the correct juxtaposition of several other protein binding sites nearby on the RNA. Such a process would explain the highly cooperative nature of the DCS assembly. It is likely that as in transcriptional regulation, controlling the splicing of an exon will require the cooperation of many proteins and that also like transcription, understanding splicing regulation will require piecing together their complex network of interactions.

\section{Materials and methods}

In vitro transcription and preparation of the RNA affinity column

The RNA transcripts for the gel mobility shift, UV cross-linking, and in vitro splicing assays were prepared as reported previously (Min et al. 1995). The transcription templates for poly-
(A)-DCS RNA were prepared by PCR using the oligonucleotides 5 ' - CGCGTAATACGACTCACTATAGGGAAAAAAAAAAAAAAAAAAAAAAAAAAAAAATGAGGCTGGGGGCTG-3' and 5'-GATGGATCCAGGAAGCACATGCAGAG-3' and using pSS10 DNA (Black 1992) as the PCR template. The resulting PCR product was gel purified and transcribed in a $150-\mu \mathrm{l}$ reaction as reported previously (Min et al. 1995) except it contained $1 \mu \mathrm{l}$ of $\left[\alpha^{-32}\right.$ P]UTP $(10 \mu \mathrm{Ci}, 800 \mathrm{Ci} /$ mmole; NEN Dupont $)$. The resulting poly(A)-DCS RNA was gel-purified, and the concentration was measured by UV absorbance.

The RNA affinity column was prepared following Siebel et al. (1994) by hybridizing 5 nmoles of poly(A)-DCS RNA to $1 \mathrm{ml}$ of poly(U)-Sepharose (Pharmacia). The poly(A)-DCS RNA was denatured in $0.5 \mathrm{M} \mathrm{KCl}$ at $75^{\circ} \mathrm{C}$ for $20 \mathrm{~min}$, added to the poly $(\mathrm{U})$ resin, and incubated at room temperature for $30 \mathrm{~min}$ with mixing. The column resin was then packed in an empty disposable minicolumn (Bio-Rad). The amount of RNA hybridized was determined by following the total radioactivity bound to the column. After extensive washing of the column with washing buffer (see below), $\sim 87 \%$ of the radioactivity was retained.

\section{Purification of KSRP}

The ultracentrifugation and ammonium sulfate precipitation steps were as described previously (Min et al. 1995). WERI-1 extract was cleared by ultracentrifugation at $360,000 \mathrm{~g}$ for 30 min in a Beckman Ti100.2 rotor. This step increased the specific binding activity of the DCS complex twofold. The supernatant from the ultracentrifugation (S360) was precipitated in $40 \%$ ammonium sulfate. The ammonium sulfate pellet (ASP40) was resuspended in half of the original volume with buffer DG (20 $\mathrm{mM}$ HEPES-KOH at $\mathrm{pH} 7.9,20 \%$ glycerol, $80 \mathrm{~mm}$ potassium glutamate, $0.2 \mathrm{~mm}$ EDTA, $0.2 \mathrm{~mm}$ PMSF, $1.0 \mathrm{~mm}$ DTT) (Min et al. 1995) and dialyzed against the same buffer. This resuspended pellet fraction showed a 25 -fold increase in the specific activity of the DCS complex binding over the $\$ 360$.

The affinity column was equilibrated at $4^{\circ} \mathrm{C}$ in binding buffer (12 mM HEPES at $\mathrm{pH} 7.9,12 \%$ glycerol, $48 \mathrm{~mm}$ potassium glutamate, $3.2 \mathrm{~mm}$ magnesium acetate, and $12 \mu \mathrm{g} / \mathrm{ml}$ heparin). The ASP40 was loaded, and the column was washed with at least 10 column volumes of binding buffer. The elution buffer was the same as the binding buffer except the potassium glutamate was replaced with $0.3,0.6,1.0$, or $2.0 \mathrm{M} \mathrm{KCl}$. The bound proteins were eluted in four steps at successively higher $\mathrm{KCl}$ concentrations using at least five column volumes at each step. The resulting fractions were dialyzed against buffer DG.

\section{Cloning of KSRP CDNAs}

The $2.0 \mathrm{M} \mathrm{KCl}$ fraction from $9.6 \mathrm{ml}$ of extract $\left(3.4 \times 10^{9}\right.$ cells $)$ was subjected to SDS-PAGE and electroblotted to a PVDF membrane (Bio-Rad). The proteins were visualized by staining the membrane with Ponceau S and excised. The protein bands were subjected to trypsin digestion. Tryptic peptides were then separated by reverse-phase HPLC on a Vydac C8 column, and individual peptides were sequenced with protein sequencer model 492 (Perkin Elmer, Applied Biosystems Division).

Multiple degenerate DNA oligonucleotides were designed from the peptide sequences and used in PCR to amplify WERI-1 cDNA, prepared with reverse transcriptase and oligo(dT) (Ausubel et al. 1987). A 660-bp PCR fragment was generated using oligonucleotides derived from peptides DAFADAVQRARQIA and LRIIGDPYK, and sequencing analysis showed that this fragment encoded other peptides (LASQGD, MMLDDI, and MILIQDGSQNTNVDK) and was thus part of a KSRP clone. WERI- 1 and LAN-5 cDNA libraries were made using the ZAP- 
cDNA synthesis kit (Stratagene). Two million plaques were screened for each library using the 660-bp fragment or part of the fragment as probes. Fifteen positive clones from the WERI-1 library and 12 from the LAN-5 library were plaque-purified, and clones $>2 \mathrm{~kb}$ were sequenced fully.

\section{Cloning of the CDNA $5^{\prime}$ end}

The 5' end of the cDNA was cloned with the 5' RACE kit (Clontech). KSRP cDNA was synthesized using oligonucleotide primer 5'-ATCAGGAGTGCTGTTATTCAC-3' (complementary to nucleotides 379-399; Fig. 2). After second-strand synthesis and ligation of the upstream primer sequence (AP1), the $5^{\prime}$ ends were amplified using the APl primer and the oligonucleotide primer 5 '-TGTCGTGGCAGCATCGCCTC-3' (complementary to nucleotides 359-378). This generated a mixed population of products and no specific bands on a gel. This population was cloned, and individual products were sequenced. Several of the RACE products contained varying amounts of KSRP cDNA sequence joined to a common leader sequence. These products contained different deletions from the L10-2 sequence that were apparently generated during the PCR amplification of the GC-rich cDNA. To confirm the presence of the common leader sequence on the KSRP mRNA, we performed $\mathrm{RT}-\mathrm{PCR}$ reactions using primers from the common leader sequence paired with primers from the L10-2 sequence.

\section{Isolation of the KSRP genomic clone}

A 182-bp PCR fragment was generated using the primers 5'CGGAATTCAATGTCGGACTACAGCCCGGGCGGGGGGTCGGCCGGGGGC-3' (containing nucleotides 239-264; Fig. 2) and $5^{\prime}$-ATCAGGAGTGCTGTTATTCAC-3' (complementary to nucleotides 379-399; Fig. 2) and clone L10-2 as the template. This fragment was used as a probe to screen a human genomic library in the Lambda Dash II vector (Stratagene) following the manufacturer's protocol. Four million plaques $(2 \times$ genomic coverage) were screened, and 11 positive clones were identified and plaque purified. The clone containing the largest insert $(20 \mathrm{~kb})$ was characterized by various restriction and Southern blot analyses. A 1.5-kb BamHI-NotI fragment hybridized to an oligonucleotide sequence (5'-GTGTGGAGCGAAGCCTTGTTCCCGCGTTGAGCCGC- $3^{\prime}$ ) derived from the 5 ' end of the RACE clone. This fragment was subcloned into pBluescriptII $\mathrm{KS}(+)$. Sequence analyses confirmed that this $1.5-\mathrm{Kb}$ fragment contained the $5^{\prime}$-most coding exon of KSRP.

\section{Gel mobility shift and UV cross-linking reactions}

The reaction conditions for the gel mobility shift and UV crosslinking assays were as described previously (Min et al. 1995), except that $1 \mu \mathrm{l}$ of ASP40 (10 $\mu \mathrm{g}$ of protein) or $7 \mu \mathrm{l}$ of each RNA affinity fraction was used. For the complementation reaction, 7 $\mu 1$ of $0.3 \mathrm{M} \mathrm{KCl}$ fraction $(0.9 \mu \mathrm{g}$ of protein) and $7 \mu \mathrm{l}$ of $2.0 \mathrm{M} \mathrm{KCl}$ fraction ( 10 ng of protein) were mixed prior to carrying out the binding reaction. For the antibody disruption of the complex (Fig. 5), the WERI-1 extract was preincubated for $8 \mathrm{~min}$ at $30^{\circ} \mathrm{C}$. Increasing amounts of purified antibody $[2.5,5.0$, or $7.5 \mu \mathrm{g}$ of total immunoglobin $\mathrm{G}(\mathrm{IgG})]$ were then added. After an additional 8 min at $30^{\circ} \mathrm{C}$ incubation with antibodies, the DCS RNA probe was then added.

\section{Anti-KSRP antibody production}

DNA fragments of the L10-2 KSRP clone coding for amino acids 172-452 (Fig. 2) or amino acids 172-711 were PCR-amplified and cloned into the GST fusion vector pGEX-4T-3 (Pharmacia). The fusion proteins were overexpressed in Escherichia coli strain BL21 and purified using the GST purification module (Pharmacia). The purified fusion proteins were sent to Caltag Laboratories for antibody production in rabbits. Antiserum C2740 is against KSRP amino acid residues 172-452, and antiserum C2742 is against residues $172-711$. Total IgG from each serum was purified on a HiTrap protein A column (Pharmacia).

\section{Antibody inhibition of N1 splicing in vitro}

The splicing reactions were performed as described previously by use of the BS-7 substrate (Chan and Black 1995; Min et al. 1995). Splicing reactions contained $50 \mu \mathrm{g}$ each of HeLa and WERI-1 nuclear extract. For the antibody inhibition experiments, increasing amounts of each purified antibody $(1.25,2.5$, or $5.0 \mu \mathrm{g}$ of total $\mathrm{IgG}$ ) were added to splicing reactions and incubated for $10 \mathrm{~min}$ at $30^{\circ} \mathrm{C}$ prior to the addition of the splicing substrate. The BS-7 substrate was then added and incubated for $4 \mathrm{hr}$ at $30^{\circ} \mathrm{C}$. For the rescue experiments, the BS-7 splicing reaction was re-optimized using half of the extract normally used (25 $\mu \mathrm{g}$ instead of $50 \mu \mathrm{g}$ each of HeLa and WERI-1 protein). This reaction can be fully inhibited by $1.5 \mu \mathrm{g}$ of C2742 total IgG. Increasing amounts of either the $2 \mathrm{M}$ affinity fraction $(66,132$, or 306 fmoles of KSRP) or purified GST-KSRP (200, 400, or 800 fmoles) were added to the antibody-inhibited reaction. These proteins were either added to extract already containing antibody (Fig. 7) or preincubated with antibody for $5 \mathrm{~min}$ at $30^{\circ} \mathrm{C}$ before addition to extract (Fig. 6C).

\section{Immunoblotting}

Immunoblotting experiments were performed as described previously (Min et al. 1995). Equal total protein (25 $\mu \mathrm{g}$ ) from HeLa and WERI-1 nuclear extract was separated by SDS-PAGE and transferred to a nitrocellulose membrane (Schleicher \& Schuell). The membrane was probed with a 1:1000 dilution of either C2740 or C2742 serum. A 1:3000 dilution of ImmunoPure horseradish peroxidase-labeled goat anti-rabbit IgG (Pierce) was used as secondary antibody. The antibody stained bands were visualized with the ELC Western Blotting Detection Kit (Amersham).

\section{Northern blotting}

These experiments were performed as described (Ausubel et al. 1987). Fifteen micrograms of total RNA from each cell line was run on a $1 \%$ formaldehyde-agarose gel. Separated RNAs were transferred to a nylon membrane (Schleicher \& Schuell) and UV cross-linked to the membrane. The blot was probed with a $350-$ bp fragment of the L10-2 clone (nucleotides 1716-2066; Fig. 2) that was labeled by the random priming kit (Amersham). The membrane was then exposed to film or PhosphorImager screen. It was then stripped and reprobed using human $\beta$-actin probe as a control.

\section{Acknowledgments}

We thank David Levens and Donald Rio for communicating results prior to publication and David Levens for the generous contribution of anti-FBP serum. We are grateful to Kristen Lynch, Juan Alfonso, Steven Smale, and members of the Black laboratory for critical comments on the manuscript. Finally, we thank Bob Horvitz for advice on nomenclature. This work was supported by the National Institutes of Health (NIH) grant R29GM49662 to D.L.B. H.M. is supported by NIH National 
Research Service Award training grant GM07185. D.L.B. is an Assistant Investigator of the Howard Hughes Medical Institute and a David and Lucile Packard Foundation Fellow.

The publication costs of this article were defrayed in part by payment of page charges. This article must therefore be hereby marked "advertisement" in accordance with 18 USC section 1734 solely to indicate this fact.

\section{Note added in proof}

The sequence data described in this paper have been submitted to GenBank under accession no. U94832.

\section{References}

Adams, M.D., D.Z. Rudner, and D.C. Rio. 1996. Biochemistry and regulation of pre-mRNA splicing. Curr. Opin. Cell Biol. 8: 331-339.

Arning, S., P. Gruter, G. Bilbe, and A. Kramer. 1996. Mammalian splicing factor SF1 is encoded by variat cDNAs and binds to RNA. RNA 2: 794-810.

Ausubel, F.M., R. Brent, R.E. Kingston, D.D. Moore, J.G. Seidman, J.A. Smith, and K. Struhl. 1987. Current protocols in molecular biology. John Wiley and Sons, New York, NY.

Balvay, L., D. Libri, M. Gallego, and M.Y. Fiszman. 1992. Intronic sequence with both negative and positive effects on the regulation of alternative transcripts of the chicken beta tropomyosin transcripts. Nucleic Acids Res. 20: 3987-3992.

Berget, S.M. 1995. Exon recognition in vertebrate splicing. I. Biol. Chem. 270: 2411-2414.

Black, D.L. 1991. Does steric interference between splice sites block the splicing of a short c-src neuron-specific exon in non-neuronal cells? Genes \& Dev. 5: 389-402.

- 1992 . Activation of c-src neuron-specific splicing by an unusual RNA element in vivo and in vitro. Cell 69: 795-807.

. 1995. Finding splice sites within a wilderness of RNA. RNA 1: 763-771.

Burke, J.F., K.E. Bright, E. Kellett, P.R. Benjamin, and S.E. Saunders. 1992. Alternative mRNA splicing in the nervous system. Prog. Brain Res. 92: 115-125.

Caputi, M., G. Casari, S. Guenzi, R. Tagliabue, A. Sidoli, C.A. Melo, and F.E. Baralle. 1994. A novel bipartite splicing enhancer modulates the differential processing of the human fibronectin EDA exon. Nucleic Acids Res. 22: 1018-1022.

Carlo, T., D.A. Sterner, and S.M. Berget. 1996. An intron splicing enhancer containing a G-rich repeat facilitates inclusion of a vertebrate micro-exon. RNA 2: 342-353.

Chan, R.C. and D.L. Black. 1995. Conserved intron elements repress splicing of a neuron-specific c-src exon in vitro. Mol. Cell. Biol. 15: 6377-6385.

Davis-Smyth, T., R.C. Duncan, T. Zhang, G. Michelotti, and D. Levens. 1996. The FBPs comprise an ancient family of singlestrand DNA binding transactivators. I. Biol. Chem. 271: 31679-31687.

Del Gatto, F. and R. Breathnach. 1995. Exon and intron sequences, respectively, repress and activate splicing of a fibroblast growth factor receptor 2 alternative exon. Mol. Cell. Biol. 15: 4825-4834.

Dirksen, W.P., R.K. Hampson, Q. Sun, and F.M. Rottman. 1994. A purine-rich exon sequence enhances alternative splicing of bovine growth hormone pre-mRNA. I. Biol. Chem. 269: 6431-6436.

Duncan, R., L. Bazar, G. Michelotti, T. Tomonaga, H. Krutzsch, M. Avigan, and D. Levens. 1994. A sequence-specific, singlestrand binding protein activates the far upstream element of c-myc and defines a new DNA-binding motif. Genes \& Dev. 8: 465-480.

Duncan, R., I. Collins, T. Tomonaga, T. Zhang, and D. Levens. 1996. A unique transactivation sequence motif is found in the carboxyl-terminal domain of the single-strand-binding protein FBP. Mol. Cell. Biol. 16: 2274-2282.

Engebrecht, J.A., K. Voelkel-Meiman, and G.S. Roeder. 1991. Meiosis-specific RNA splicing in yeast. Cell 66: 1257-1268.

Frohman, M.A. 1993. Rapid amplification of complimentary DNA ends for generation of full-length complimentary cDNAs: Thermal RACE. Methods Enzymol. 218: 340-359.

Fu, X.D. 1995. The superfamily of arginine/serine-rich splicing factors. RNA 1: 663-680.

Fu, X.D., R.A. Katz, A.M. Skalka, and T. Maniatis. 1991. The role of branchpoint and $3^{\prime}$-exon sequences in the control of balanced splicing of avian retrovirus RNA. Genes \& Dev. 5: 211-220.

Hodges, D. and S.I. Bernstein. 1994. Genetic and biochemical analysis of alternative RNA splicing. Adv. Genet. 31: 207281.

Huh, G.S. and R.O. Hynes. 1994. Regulation of alternative premRNA splicing by a novel repeated hexanucleotide element. Genes \& Dev. 8: 1561-1574.

Inoue, K., M. Ohno, and Y. Shimura. 1995. Aspects of splice site selection in constitutive and alternative pre-mRNA splicing. Gene Expression 4: 177-182.

Kozak, M. 1986. Point mutations define a sequence flanking the AUG initiator codon that modulates translation by eukaryotic ribosomes. Cell 44: 283-292.

Kramer, A. 1995. The biochemistry of pre-mRNA splicing. In Pre-mRNA Processing (ed. A.I. Lamond), pp. 35-64. R.G. Landes, Austin, TX.

Lavigueur, A., B.H. La, A.R. Kornblihtt, and B. Chabot. 1993. A splicing enhancer in the human fibronectin alternate ED1 exon interacts with SR proteins and stimulates U2 snRNP binding. Genes \& Dev. 7: 2405-2417.

Levy, J.B., T. Dorai, L.H. Wang, and J.S. Brugge. 1987. The structurally distinct form of pp60c-src detected in neuronal cells is encoded by a unique c-src mRNA. Mol. Cell. Biol. 7: 41424145 .

Lou, H., Y. Yang, G.J. Cote, S.M. Berget, and R.F. Gagel. 1995. An intron enhancer containing a $5^{\prime}$ splice site sequence in the human calcitonin/calcitonin gene-related peptide gene. Mol. Cell. Biol. 15: 7135-7142.

Lynch, K.W. and T. Maniatis. 1995. Synergistic interactions between two distinct elements of a regulated splicing enhancer. Genes \& Dev. 9: 284-293.

- 1996. Assembly of specific SR protein complexes on distinct regulatory elements of the Drosophila doublesex splicing enhancer. Genes \& Dev. 10: 2089-2101.

Manley, J.L. and R. Tacke. 1996. SR proteins and splicing control. Genes \& Dev. 10: 1569-1579.

Martinez, R., P.B. Mathey, A. Bernards, and D. Baltimore. 1987. Neuronal pp60c-src contains a six-amino acid insertion relative to its non-neuronal counterpart. Science 237: 411-415.

McKeown, M. 1992. Alternative mRNA splicing. Annu. Rev. Cell Biol. 8: 133-155.

Min, H., R.C. Chan, and D.L. Black. 1995. The generally expressed hnRNP $F$ is involved in a neural-specific pre-mRNA splicing event. Genes \& Dev. 9: 2659-2671.

Moore, M.J., C.C. Query, and P.A. Sharp. 1993. Splicing of precusors to mRNA by the spliceosome. In The RNA world: The nature of modern RNA suggests a prebiotic RNA world (ed. R.F. Gesteland and J.F. Atkins), pp. 303-357. Cold Spring Harbor Laboratory Press, Cold Spring Harbor, NY.

Musco, G., G. Stier, C. Joseph, M.A. Castiglione Morelli, M. 
Min et al.

Nilges, T.J. Gibson, and A. Pastore. 1996. Three-dimensional structure and stability of the $\mathrm{KH}$ domain: Molecular insights into the fragile X syndrome. Cell 85: 237-245.

Nandabalan, K. and G.S. Roeder. 1995. Binding of a cell-typespecific RNA splicing factor to its target regulatory sequence. Mol. Cell. Biol. 15: 1953-1960.

Ramchatesingh, J., A.M. Zahler, K.M. Neugebauer, M.B. Roth, and T.A. Cooper. 1995. A subset of SR proteins activates splicing of the cardiac troponin $\mathrm{T}$ alternative exon by direct interactions with an exonic enhancer. Mol. Cell. Biol. 15: 4898-4907.

Reddy, R. and H. Busch. 1988. Small nuclear RNAs: RNA sequences, structures, and modifications. In Structure and function of major and minor small nuclear ribonucleoprotein particles (ed. M.L. Birnstiel), pp. 1-37. Springer-Verlag, Berlin, Germany.

Rio, D.C. 1993. Splicing of pre-mRNA: Mechanism, regulation and role in development. Curr. Opin. Genet. Dev. 3: 574584.

Ryan, K.J. and T.A. Cooper. 1996. Muscle-specific splicing enhancers regulate inclusion of the cardiac troponin $\mathrm{T}$ alternative exon in embryonic skeletal muscle. Mol. Cell. Biol. 16: 4014-4023.

Schwartz, R.M. and M.O. Dayhoff. 1979. Atlas of protein sequence and structure (ed. M.O. Dayhoff), pp. 353-358. National Biomedical Research Foundation, Washington, D.C.

Siebel, C.W., L.D. Fresco, and D.C. Rio. 1992. The mechanism of somatic inhibition of Drosophila P-element pre-mRNA splicing: Multiprotein complexes at an exon pseudo-5' splice site control U1 snRNP binding. Genes \& Dev. 6: 1386-1401.

Siebel, C.W., R. Kanaar, and D.C. Rio. 1994. Regulation of tissue-specific P-element pre-mRNA splicing requires the RNA-binding protein PSI. Genes \& Dev. 8: 1713-1725.

Siebel, C.W., A. Admon, and D.C. Rio. 1995. Soma-specific expression and cloning of PSI, a negative regulator of $\mathrm{P}$ element pre-mRNA splicing. Genes \& Dev. 9: 269-283.

Siomi, H., M.J. Matunis, W.M. Michael, and G. Dreyfuss. 1993. The pre-mRNA binding $\mathrm{K}$ protein contains a novel evolutionarily conserved motif. Nucleic Acids Res. 21: 11931198.

Siomi, H., M. Choi, M.C. Siomi, R.L. Nussbaum, and G. Dreyfuss. 1994. Essential role for $\mathrm{KH}$ domains in RNA binding: Impaired RNA binding by a mutation in the $\mathrm{KH}$ domain of FMR1 that causes fragile X syndrome. Cell 77: 33-39.

Sirand-Pugnet, P., P. Durosay, E. Brody, and J. Marie. 1995. An intronic (A/U)GGG repeat enhances the splicing of an alternative intron of the chicken beta-tropomyosin pre-mRNA. Nucleic Acids Res. 23: 3501-3507.

Staknis, D. and R. Reed. 1994. SR proteins promote the first specific recognition of pre-mRNA and are present together with the Ul small nuclear ribonucleoprotein particle in a general splicing enhancer complex. Mol. Cell. Biol. 14: 7670-7682.

Sun, Q., A. Mayeda, R.K. Hampson, A.R. Krainer, and F.M. Rottman. 1993. General splicing factor SF2/ASF promotes alternative splicing by binding to an exonic splicing enhancer. Genes \& Dev. 7: 2598-2608.

Tanaka, K., A. Watakabe, and Y. Shimura. 1994. Polypurine sequences within a downstream exon function as a splicing enhancer. Mol. Cell. Biol. 14: 1347-1354.

Tian, M. and T. Maniatis. 1994. A splicing enhancer exhibits both constitutive and regulated activities. Genes \& Dev. 8: 1703-1712.

Valcárcel, J. and M.R. Green. 1996. The SR protein family: Pleiotropic functions in pre-mRNA splicing. Trends Biochem. Sci. 21: 296-301.
Wang, Z., H.M. Hoffmann, and P.J. Grabowski. 1995. Intrinsic $\mathrm{U} 2 \mathrm{AF}$ binding is modulated by exon enhancer signals in parallel with changes in splicing activity. RNA 1: 21-35.

Watakabe, A., K. Tanaka, and Y. Shimura. 1993. The role of exon sequences in splice site selection. Genes \& Dev. 7: 407-418. 


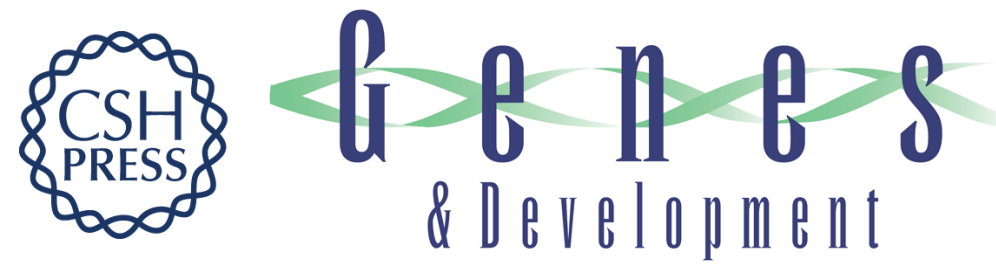

\section{A new regulatory protein, KSRP, mediates exon inclusion through an intronic splicing enhancer.}

H Min, C W Turck, J M Nikolic, et al.

Genes Dev. 1997, 11:

Access the most recent version at doi:10.1101/gad.11.8.1023

References This article cites 51 articles, 32 of which can be accessed free at:

http://genesdev.cshlp.org/content/11/8/1023.full.html\#ref-list-1

License

Email Alerting

Service

Receive free email alerts when new articles cite this article - sign up in the box at the top right corner of the article or click here.

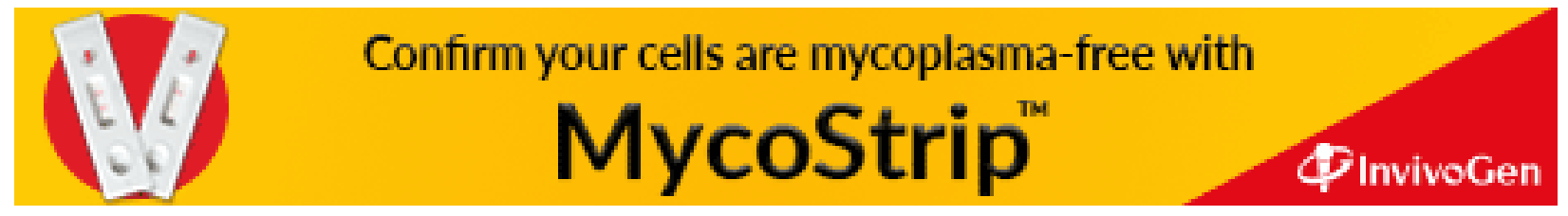

